\title{
The Mechanism of Oxidative Alkoxyamine Cleavage: The Surprising Role of Solvent and Supporting Electrolyte
}

\author{
Benjamin B. Noble, ${ }^{1}$ Philip L. Norcott, ${ }^{1}$ Chelsey L. Hammill, ${ }^{1}$ Simone Ciampi, ${ }^{2 *}$ Michelle L. Coote ${ }^{1 *}$ \\ ${ }^{1}$ ARC Centre of Excellence for Electromaterials Science, Research School of Chemistry, Australian National University, \\ Canberra, Australian Capital Territory 2601, Australia \\ ${ }^{2}$ School of Molecular and Life Sciences, Curtin Institute of Functional Molecules and Interfaces, Curtin University, \\ Bentley, Western Australia 6102, Australia
}

Supporting Information Placeholder

ABSTRACT: In this work we show that the nature of the supporting electrolyte and solvent can dramatically alter the outcome of the electrochemically mediated cleavage of alkoxyamines. A combination of cyclic voltammetry (CV) experiments and quantum chemistry is used to study the oxidation behavior of TEMPO-i-Pr under different conditions. In dichloromethane, using a non-coordinating electrolyte $\left(\mathrm{TBAPF}_{6}\right)$, TEMPO-i-Pr undergoes reversible oxidation, which indicates that the intermediate radical-cation is stable towards mesolytic fragmentation. In contrast, in tetrahydrofuran with the same electrolyte, oxidized TEMPO- $i$-Pr undergoes a rapid and irreversible fragmentation. In nitromethane and acetonitrile, partially irreversible oxidation is observed, indicating that fragmentation is much slower. Likewise, alkoxyamine oxidation in the presence of more strongly coordinating supporting electrolyte anions $\left(\mathrm{BF}_{4}^{-}, \mathrm{ClO}_{4}^{-}, \mathrm{OTf}^{-}, \mathrm{HSO}_{4}^{-}, \mathrm{NO}_{3}^{-}\right)$is also irreversible. These observations can be explained in terms of solvent- or electrolyte-mediated $\mathrm{S}_{\mathrm{N}} 2$ pathways, and indicate that oxidative alkoxyamine cleavage can be 'activated' by introducing coordinating solvents or electrolytes or 'inhibited' through the use of non-coordinating solvents and electrolytes.

\section{INTRODUCTION}

Alkoxyamines are well-known for their crucial role in Nitroxide Mediated Polymerization (NMP), ${ }^{1-3}$ undergoing reversible homolysis to generate an initiating carbon-centered radical and persistent nitroxide. Unfortunately, relatively high temperatures (ca. 80$120{ }^{\circ} \mathrm{C}$ ) are required to achieve sufficient levels of alkoxyamine homolysis, and at those temperatures unwanted side-reactions can limit the scope and utility of NMP.4-6 To address these problems, various groups have examined using alternative stimuli to trigger alkoxyamine fragmentation, including light ${ }^{7-9}$

and chemical additives, ${ }^{10-11}$ with mixed success. Recently, we demonstrated that both charged-functional groups ${ }^{12-14}$ and electric fields ${ }^{15}$ can be used to induce alkoxyamine homolysis.

While exploring the use of electric fields generated in cyclic voltammetry (CV) experiments, we found that alkoxyamines could undergo a one-electron oxidation followed by mesolytic fragmentation (see Scheme 1). ${ }^{15}$ In our original work, the alkoxyamine in question, TEMPO- $\mathrm{CH}\left(\mathrm{CH}_{3}\right) \mathrm{Ph}$, underwent an oxidation process that could be described by an $\mathrm{EC}_{\text {irr }} \mathrm{E}$ mechanism; with initial electrochemical oxidation of the alkoxyamine, irreversible chemical decomposition to produce TEMPO radicals and ${ }^{+} \mathrm{CH}\left(\mathrm{CH}_{3}\right) \mathrm{Ph}$ cations and subsequent electrochemical oxidation of the nitroxide. ${ }^{15}$ Obviously, these fragmentation patterns suggest that electrochemical cleavage would be an unsuitable trigger for traditional NMP but raise the exciting possibility of in situ "on demand" carbocation generation for synthesis, ${ }^{16-17}$ surface modification ${ }^{18}$ and tandem radical-cationic polymerizations. ${ }^{19-20}$

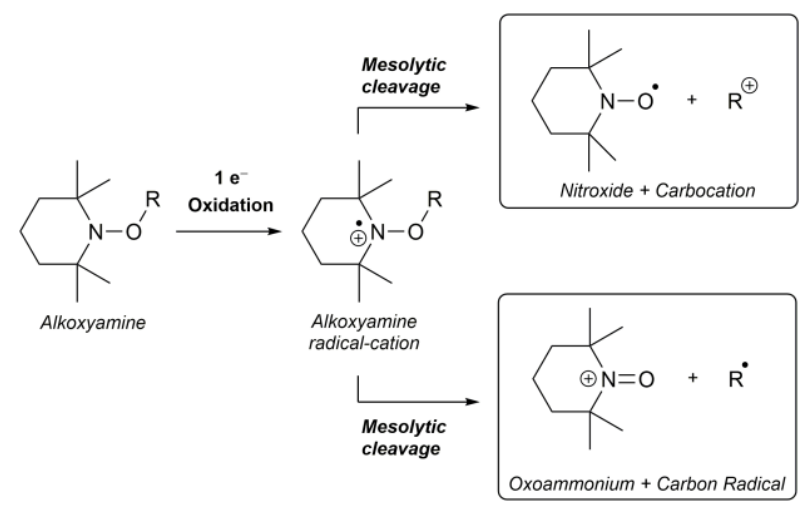

Scheme 1. Electrochemical cleavage of alkoxyamines and their subsequent fragmentation pathways. 
While our original study ${ }^{15}$ highlighted the potential use of electrochemistry as a trigger for alkoxyamine cleavage, the actual fragmentation mechanism was somewhat contentious. Experimentally, the CV data indicated unambiguously that the unimolecular decomposition of oxidized TEMPO- $\mathrm{CH}\left(\mathrm{CH}_{3}\right) \mathrm{Ph}$ was exceedingly rapid $\left(\mathrm{k}_{\text {frag }} \sim 10^{6} \mathrm{~s}^{-1}\right)$, and irreversible. In contrast, high-level theoretical calculations predicted that the unmediated cleavage of the TEMPO$\mathrm{CH}\left(\mathrm{CH}_{3}\right) \mathrm{Ph}$ radical-cation is slow and thermodynamically unfavorable. Despite this discrepancy, theoretical predictions for the oxidation potentials of all the component species were in excellent agreement with experimental values, suggesting that the problem was not with the level of theory itself. 15

Previous work indicated that the precise chemical environment of the double-layer could influence the oxidation behavior of Si(100)-grafted TEMPO radicals, as the supporting electrolyte predictably shifted the oxidation potential via ion-pairing. ${ }^{21}$ While similar calculations on TEMPO-CH( $\left(\mathrm{CH}_{3}\right) \mathrm{Ph}$ hinted that solvent or supporting electrolyte could promote oxidative fragmentation, changing the conditions did not significantly affect the experimentally observed CV results. Follow-up theoretical and experimental studies of a wide test set of TEMPO-based alkoxyamines in acetonitrile with (n-Bu) ${ }_{4} \mathrm{NClO}_{4}\left(\mathrm{TBAClO}_{4}\right)$ as an electrolyte showed a diversity of oxidation behavior. ${ }^{22}$ Depending on the leaving group, oxidation was either reversible, partially reversible or completely irreversible.

While oxidative cleavage of alkoxyamines promises to offer a convenient "on demand" route to carbocations, it would be enormously beneficial to clarify the precise mechanism of their fragmentation. Conversely, as species with reversible redox characteristics are often of interest for energy storage applications, ${ }^{23-27}$ suppressing alkoxyamine fragmentation is also of interest. To better understand the factors involved in alkoxyamine cleavage, we explored the $\mathrm{CV}$ behavior of a TEMPO-based alkoxyamine, TEMPO-i-Pr. This species showed partially reversible oxidation and a slower $\mathrm{k}_{\text {frag }}\left(\sim 0.3 \mathrm{~s}^{-1}\right)$ in acetonitrile with $\mathrm{TBAClO}_{4}$ electrolyte, ${ }^{22}$ and thus is a good candidate for manipulation based on the reaction conditions. In conjunction with this experimental work, we used high-level calculations to study the effect of different electrolytes and solvents on this process.

\section{EXPERIMENTAL AND COMPUTATIONAL METHODS}

General Experimental. Starting materials were purchased from commercial sources unless otherwise stated. Brine refers to a saturated aqueous solution of $\mathrm{NaCl}$. Petrol refers to the fraction of petroleum ether boiling in the range $40-60{ }^{\circ} \mathrm{C}$. All synthetic reactions were conducted open to the air. All compounds, reagents and solvents were purchased from commercial sources and used as supplied unless otherwise stated. Flash column chromatography was carried out using Merck silica gel 60 (0.04-0.063 mm, 230-400 mesh). Thin layer chromatography was carried out using Merck $\mathrm{F}_{254}$ aluminium-backed silica plates and visualized using UV light (254 and $365 \mathrm{~nm}$ ) or potassium permanganate solution. All NMR spectra were obtained at $298 \mathrm{~K}$ on a Bruker AVANCE $400{ }^{1} \mathrm{H}$ at 400.1 $\mathrm{MHz}$ and ${ }^{13} \mathrm{C}$ at $100.5 \mathrm{MHz}$ ). Chemical shifts are quoted as parts per million (ppm) and referenced to $\mathrm{CHCl}_{3}\left(\delta_{\mathrm{H}}\right.$ 7.26) or $\mathrm{CDCl}_{3}\left(\delta_{\mathrm{C}} 77.16\right)$. High Resolution Mass Spectrometry data was obtained on an Orbitrap QE plus mass spectrometer.

Cyclic Voltammetry. Electrochemical experiments were carried out using a PalmSens4 Potentiostat/Galvanostat/Impedance Analyzer and a single compartment three-electrode glass cell. The working electrode was either glassy carbon or gold disks with an active area of $0.064-0.065 \mathrm{~cm}^{2}$, electrochemically determined from refinement of an $\mathrm{E}$ model against experimental voltammograms measured in $7.1 \times 10^{-2} \mathrm{M}$ $\mathrm{MeCN} / \mathrm{Bu}_{4} \mathrm{NClO}_{4}$ in the presence of $1.0 \times 10^{-3} \mathrm{M}$ ferrocene. $\mathrm{Ag} / \mathrm{AgCl}$ was used as the reference electrode and platinum wire as the counter electrode. Alkoxyamine $(2 \mathrm{mM})$ and electrolyte (TBA salts, $1.0 \times 10^{-1} \mathrm{M}$ ) was dissolved in $10 \mathrm{~mL}$ of dried solvent $\left(\mathrm{MeCN}, \mathrm{CH}_{2} \mathrm{Cl}_{2}\right.$, $\mathrm{MeNO}_{2}$, or THF). In the case of $\mathrm{TBAHSO}_{4}$, the electrolyte concentration was $\left(2.0 \times 10^{-1} \mathrm{M}\right)$. The solution was sparged with argon prior to analysis. All cyclic voltammograms were obtained after bubbling, with no stirring. Digital simulations of cyclic voltammetry data were performed in DigiElch-Professional v7 (ElchSoft). Butler-Volmer kinetics was used to estimate charge transfer parameters and we assumed a semi-infinite 1D diffusion. The cell iR drop was not compensated during measurement. Values of cell resistance were measured by electrochemical impedance spectroscopy and used in the simulations. Adsorption steps were neglected in the simulations and the transfer coefficients for both electron transfer reactions (TEMPO/oxoammonium and alkoxyamine/alkoxyamine $\left.{ }^{\bullet+}\right)$ were assumed as constants $(\alpha$, $0.5)$ for fitting purposes. For the chemical step, only the forward $\left(k_{f}\right)$ constant is considered. The secondorder backward $\left(k_{b}\right)$ constant tends to zero (i.e. backward chemical reaction is not operative in the time scale of the experiments).

Synthesis of TEMPO-iPr. TEMPO-iPr was prepared in an analogous fashion to that described previously, ${ }^{22}$ to give a colourless oil; ${ }^{1} \mathrm{H}$ NMR $\left(400 \mathrm{MHz} ; \mathrm{CDCl}_{3}\right) 3.98$ (sept, $J=6.2 \mathrm{~Hz}, 1 \mathrm{H}), 1.45-1.10\left(\mathrm{~m}, 6 \mathrm{x} \mathrm{CH}_{3}\right.$ and $3 \mathrm{x}$ $\left.\mathrm{CH}_{2}, 24 \mathrm{H}\right) ;{ }^{13} \mathrm{C}$ NMR (100 MHz; $\left.\mathrm{CDCl}_{3}\right) 75.1(\mathrm{CH}), 59.5$ (C), $40.3\left(\mathrm{CH}_{2}\right), 34.5\left(\mathrm{CH}_{3}\right), 22.4\left(\mathrm{CH}_{3}\right), 20.3\left(\mathrm{CH}_{3}\right), 17.4$ 
$\left(\mathrm{CH}_{2}\right)$; HRMS $m / z$ calculated for $\mathrm{C}_{12} \mathrm{H}_{26} \mathrm{NO}^{+}(\mathrm{M}+\mathrm{H})^{+}$ 200.2009, found 200.2010 (+ 0.345 ppm error).

Computational Procedures. All standard $a b$ initio molecular orbital theory and density functional theory (DFT) calculations were carried out using Gaussian $09^{28}$ and Molpro $^{29}$ software packages. Procedures were chosen based on benchmarking against experiment in previous studies of similar systems. ${ }^{15,} 22 \mathrm{Ge}-$ ometries were optimized at the M06-2X/6$31+G(d, p)^{30}$ level of theory, and frequencies were also calculated at this level. Single point energies were calculated using the high-level composite $a b$ initio method G3(MP2)CC(+), which is a variant of G3(MP2)CC 31 where the calculations with the 6$31 \mathrm{G}(\mathrm{d})$ basis set are replaced with corresponding 6$31+G(d)$ calculations to allow for better treatment of the anionic species. These high-level calculations were utilized in conjunction with the ONIOM style approximation for larger systems, ${ }^{32-33}$ where the full system was modelled using UMP2/GTMP2Large//M06-2X/6$31+G(d, p)$ (see Supporting Information).

Gibbs free energies in solution were calculated via a thermocycle in which Gibbs free energies in the gas phase, as calculated via standard ideal gas partition functions, were combined with Gibbs free energies of solvation and the necessary phase change correction term. ${ }^{34}$ The SMD solvent model ${ }^{35}$ was used to correct for implicit solvent effects, and where noted below, this was used in conjunction with explicit solvent molecules. For this purpose, geometries were fully optimized in solution at the M06-2X/6-31+G(d,p) level.

For oxidation in the various solvents, potentials were calculated via the Nernst equation using literature values of the respective reference electrodes (see Supporting Information for details). For the study of electrolyte effects in DCM, the isodesmic method was used using the (reversible) experimental oxidation potential of the $\mathrm{TBAPF}_{6} / \mathrm{DCM}$.

\section{RESULTS AND DISCUSSION}

Solvent Effects. To examine the potential impact of solvent on the oxidative fragmentation process, a CV study of TEMPO-i-Pr was performed in acetonitrile (ACN), tetrahydrofuran (THF), nitromethane (NM) and dichloromethane (DCM). These solvents were chosen so that the influence of dielectric permittivity $(\varepsilon)$ and Lewis basicity could be examined separately; with ACN and NM possessing relatively similar high $\varepsilon$ values (but markedly different Lewis basicities) and THF and DCM possessing relatively similar low $\varepsilon$ values. The obtained CV data for these systems in different solvent systems are shown in Figure 1.

TEMPO-i-Pr oxidation was found to be irreversible in THF, partially irreversible in ACN, mostly reversible in NM, and completely reversible in DCM. This is consistent with the rate coefficients for the fragmentation reaction, modelled as an $S_{\mathrm{N}} 2$ reaction with a solvent molecule, as fitted to the CV scans, (see Table 1). These data suggest that Lewis basicity, rather than dielectric constant, is the key factor driving mesolytic cleavage. Indeed, the observed fragmentation rates follow the same ordering as the Gutmann donor number ${ }^{36}$ of the respective solvents (THF $>$ ACN $>$ NM $>$ DCM).
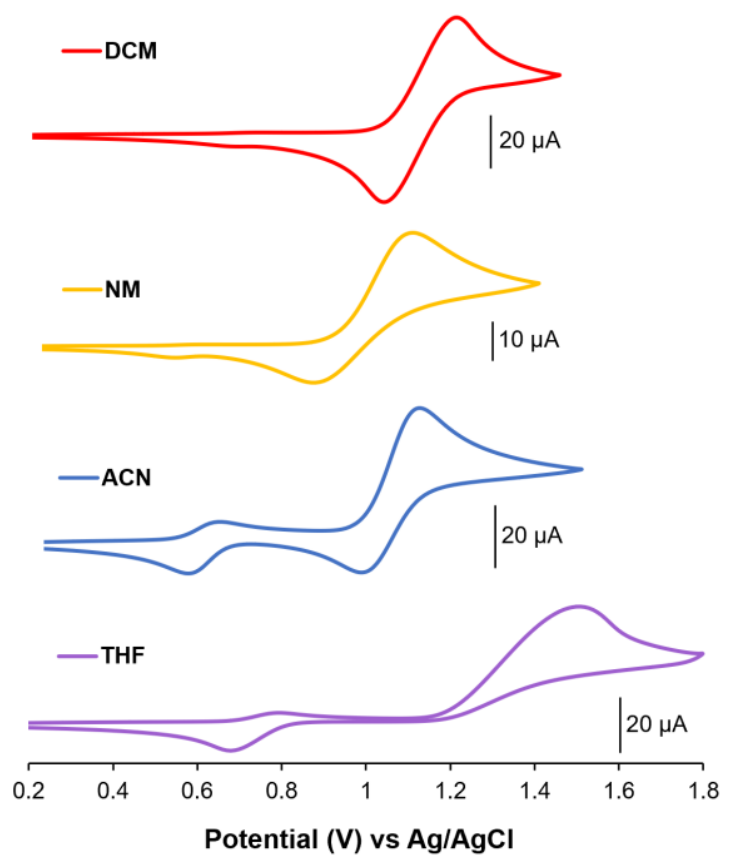

Figure 1. Effect of solvent coordination on the reversibility of TEMPO-i-Pr oxidation with TBAPF $_{6}$ electrolyte.

To help rationalize these experimental results in terms of the underlying interactions, we also examined the energetics of TEMPO-i-Pr oxidation and subsequent reaction using high-level ab initio molecular orbital theory (under analogous solvation conditions to the respective $\mathrm{CV}$ experiments). These calculations reveal that unimolecular fragmentation of oxidized TEMPO-i-Pr to form TEMPO and 'free' isopropyl carbocations is prohibitively slow and thermodynamically unfavorable in all solvents examined (Figure 2). However, for ACN, THF and NM, cleavage via a solvent mediated $\mathrm{S}_{\mathrm{N}} 2$ pathway was possible, though only thermodynamically favorable in the case of ACN and THF.

Theoretical predictions of the fragmentation rate coefficient are within the correct order of magnitude of those derived from the experimental CV data and follow the same qualitative order (see Table 1). These computational results clearly indicate that strongly coordinating solvents can mediate the cleavage of 
Table 1. Theoretical and Experimental oxidation potential ( $\mathrm{V} \mathrm{vs} \mathrm{Ag} / \mathrm{AgCl}$ ) for TEMPO-i-Pr and $\mathrm{S}_{\mathrm{N}} 2$ rate coefficient (L $\left.\mathrm{mol}^{-1} \mathrm{~s}^{-1}\right)$ with solvent $(k \mathrm{~s})$ and/or electrolyte $\left(k_{\mathrm{E}}\right)^{\mathrm{a}}$

\begin{tabular}{|c|c|c|c|c|c|c|}
\hline \multirow[t]{2}{*}{ Solvent } & \multirow[t]{2}{*}{ Electrolyte } & \multicolumn{2}{|c|}{ E (V vs Ag/AgCl) } & \multicolumn{3}{|c|}{$\mathrm{S}_{\mathrm{N}} 2$ Rate Coefficient $\mathrm{k}\left(\mathrm{L} \mathrm{mol}^{-1} \mathrm{~s}^{-1}\right)$} \\
\hline & & experiment & theory & $\mathrm{ks}_{\mathrm{S}}$ or $\mathrm{k}_{\mathrm{E}}$ & experiment & theory \\
\hline THF & $\mathrm{TBA} \mathrm{PF}_{6}$ & $1.29 \pm 0.01$ & 1.10 & $k_{\mathrm{s}}$ & $0.075 \pm 0.006$ & 0.023 \\
\hline $\mathrm{ACN}$ & $\mathrm{TBA}-\mathrm{PF}_{6}$ & $1.03 \pm 0.00$ & 0.85 & $k_{\mathrm{S}}$ & $0.006 \pm 0.001$ & 0.0006 \\
\hline NM & $\mathrm{TBA}-\mathrm{PF}_{6}$ & $0.96 \pm 0.00$ & 0.71 & $k \mathrm{~s}$ & $0.0003 \pm 0.0001$ & 0.0001 \\
\hline DCM & $\mathrm{TBA}-\mathrm{PF}_{6}$ & $1.11 \pm 0.00$ & 0.98 & & - & - \\
\hline DCM & $\mathrm{TBA}_{-}-\mathrm{BF}_{4}$ & $1.21 \pm 0.00$ & 1.20 & $k_{\mathrm{E}}$ & $2.5 \pm 0.0$ & 1.12 \\
\hline DCM & $\mathrm{TBA}^{-\mathrm{ClO}_{4}}$ & $1.17 \pm 0.00$ & 1.07 & $k_{\mathrm{E}}$ & $10.2 \pm 0.6$ & 37.6 \\
\hline DCM & TBA-OTf & $1.19 \pm 0.00$ & 1.10 & $k_{\mathrm{E}}$ & $15.0 \pm 0.8$ & 137 \\
\hline DCM & ${\mathrm{TBA}-\mathrm{HSO}_{4}}_{4}$ & $1.35 \pm 0.00$ & 1.18 & $k_{\mathrm{E}}$ & $45.3 \pm 4.1$ & 250 \\
\hline DCM & TBA-NO ${ }_{3}$ & $1.26 \pm 0.01$ & 1.01 & $k_{\mathrm{E}}$ & $13316 \pm 2186$ & 7950 \\
\hline
\end{tabular}

${ }^{a}$ Electrochemical formal potential of the alkoxyamine/alkoxyamine ${ }^{\bullet+}$ redox couple, as estimated from digital simulations of experimental $\mathrm{CV}$ data. The fragmentation reaction is a second order $\mathrm{S}_{\mathrm{N}} 2$ process with solvent and/or electrolyte. Calculations carried out at G3(MP2,CC)(+)//M06-2X/6-31+G(d,p), see text. For electrolytes other than $\mathrm{TBAPF}_{6}$, theoretical oxidation potentials were refer-

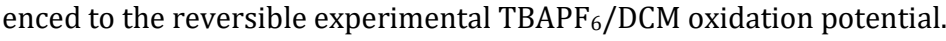

alkoxyamine radical-cations by stabilizing the fragment carbocation as an explicit adduct. In contrast, weak donor solvents (NM and DCM) are unable to effectively stabilize the $i$ - $\mathrm{Pr}^{+}$fragment and at best only marginally promote the otherwise highly unfavorable fragmentation process.

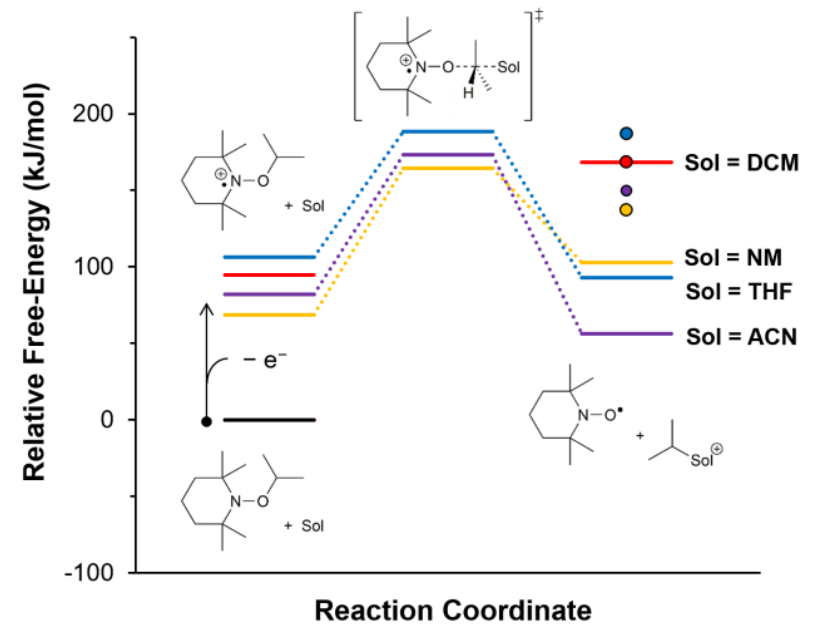

Figure 2. PES showing the energetics of TEMPO-i-Pr oxidation and cleavage in the presence of different solvents. Dots indicated predicted cleavage energy in continuum solvent, while the lines indicate explicit solvent mediated cleavage. Unlike the other solvents, DCM did not form a stable complex with an isopropyl cation.

Electrolyte Effects. Having established the crucial role of solvent nucleophilicity on alkoxyamine oxidative cleavage, next we examined the potential influence of supporting electrolyte. Utilizing DCM as a noncoordinating solvent (to exclude solvent effects on alkoxyamine radical-cation cleavage), different tetra$n$-butylammonium (TBA) salts encompassing a range of Lewis basicities were investigated. The anions of these salts ranged from $\mathrm{PF}_{6}{ }^{-}$and $\mathrm{BF}_{4}-$ (usually considered "non-coordinating"), to $\mathrm{OTf}^{-}$and $\mathrm{ClO}_{4}^{-}$(very weakly coordinating), to $\mathrm{HSO}_{4}^{-}$and $\mathrm{NO}_{3}{ }^{-}$(weakly coordinating). The obtained $\mathrm{CV}$ data for these systems are presented in Figure 3, while fitted oxidation potentials and rate coefficients are included in Table 1.

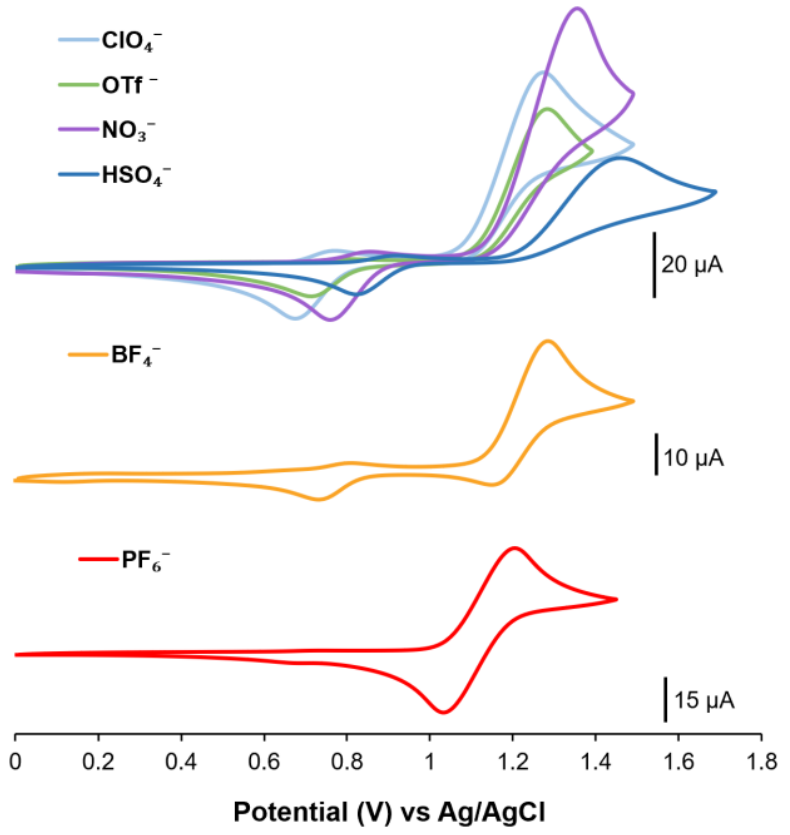

Figure 3. Effect of supporting electrolyte on the reversibility of TEMPO- $i$-Pr oxidation in DCM.

As illustrated in Figure 3, TEMPO-i-Pr cleavage is observed with all electrolytes except for $\mathrm{TBAPF}_{6}$, which is the least coordinating of those studied. The fragmentation rate coefficients approximately follow the same ordering as Lewis basicity, decreasing from $\mathrm{NO}_{3}$ $>\mathrm{HSO}_{4^{-}}>\mathrm{OTf}^{-} \sim \mathrm{ClO}_{4^{-}}>\mathrm{BF}_{4}^{-}$. Surprisingly, noticea- 
ble fragmentation was observed even with the relatively noncoordinating $\mathrm{TBABF}_{4}$ as the supporting electrolyte. To help rationalize these underlying electrolyte interactions, high-level computational theory was used to explore the mesolytic fragmentation process (see Figure 4).

The kinetic and thermodynamic favorability of TEMPO- $i$-Pr radical-cation fragmentation is strongly dependent on the identity of the supporting electrolyte anion. Relatively Lewis basic anions, such as $\mathrm{NO}_{3}{ }^{-}$ and $\mathrm{HSO}_{4}^{-}$, dramatically stabilize the $i-\mathrm{Pr}^{+}$fragment as an organo-nitrate and organo-bisulfate, respectively. Indeed, cleavage of TEMPO- $i$-Pr radical-cations in the presence of $\mathrm{NO}_{3}{ }^{-}$and $\mathrm{HSO}_{4}{ }^{-}$via an electrolyte anionmediated $\mathrm{S}_{\mathrm{N}} 2$ pathway was found to have small barriers and highly favorable reaction free-energies (c.a. $-100 \mathrm{~kJ} / \mathrm{mol}$ and $-75 \mathrm{~kJ} / \mathrm{mol}$, respectively). Indeed, the electrolyte anion-mediated $\mathrm{S}_{\mathrm{N}} 2$ pathway was found to be highly favorable (ca. $-50 \mathrm{~kJ} / \mathrm{mol}$ ) even with the weakly coordinating anions $\mathrm{ClO}_{4}^{-}$and OTf-.

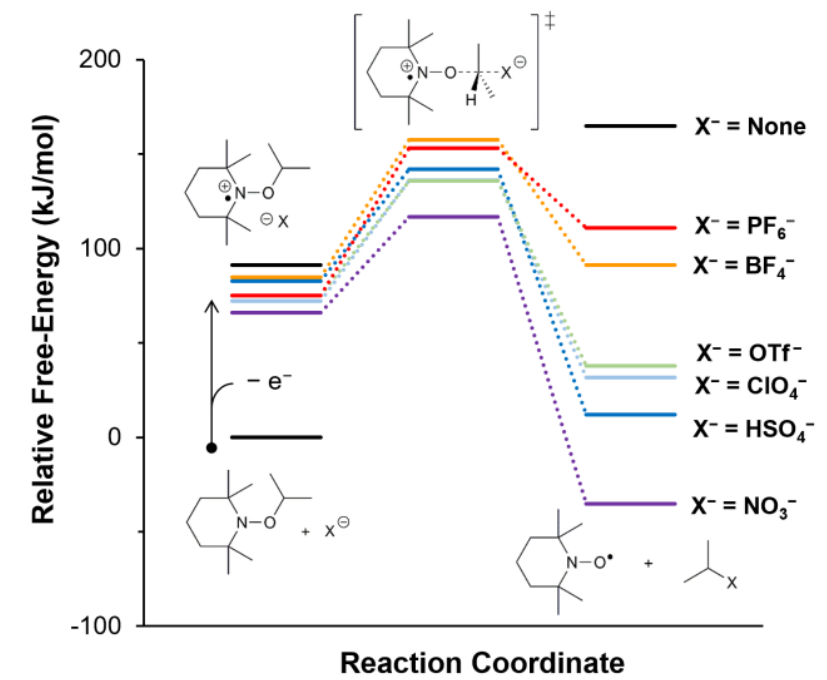

Figure 4. PES showing the energetics of TEMPO- $i$-Pr oxidation and cleavage in the presence of different supporting electrolyte anions in DCM.

Interestingly, $\mathrm{BF}_{4}^{-}$and $\mathrm{PF}_{6}^{-}$showed somewhat unique behavior in that their respective ion-pairs with the $i$ - $\mathrm{Pr}^{+}$cation were found to be strongly susceptible to fluoride transfer to generate $i-\mathrm{Pr}-\mathrm{F}$ and $\mathrm{BF}_{3}$ or $\mathrm{PF}_{5}$, respectively (Scheme 2). In the case of $\mathrm{BF}_{4}{ }^{-}$, this fluoride transfer process results in an essentially thermoneutral overall cleavage free-energy, which is consistent with the observed CV behavior. However, in the case of $\mathrm{PF}_{6}^{-}$, cleavage was found to be thermodynamically unfavorable, even when this fluoride transfer reaction was considered. Excitingly, this reaction with $\mathrm{BF}_{4}^{-}$suggests a potential new in situ method for fluorination. ${ }^{37}$

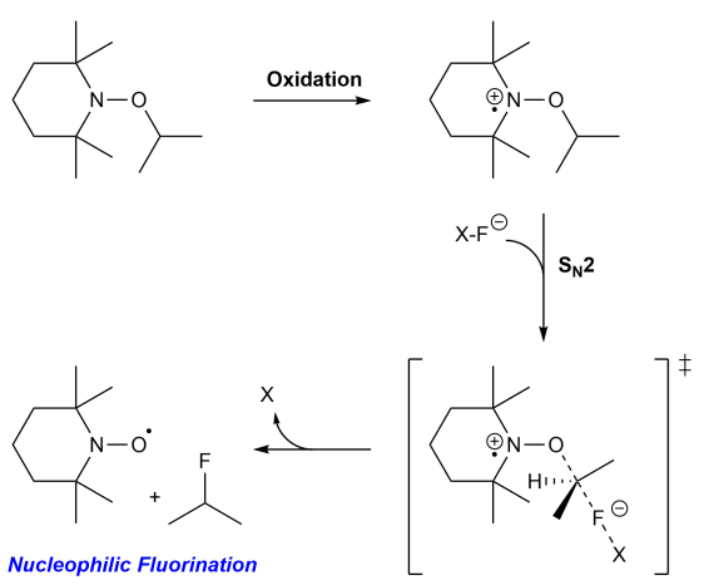

Scheme 2. Proposed $\mathrm{S}_{\mathrm{N}} 2$ cleavage of TEMPO- $i$-Pr with fluoridecontaining electrolytes. Here $\mathrm{X}=\mathrm{BF}_{3}$ or $\mathrm{PF}_{5}$

\section{CONCLUSION}

In summary, these theoretical and experimental results reveal and rationalize the critical but underappreciated role that solvents and supporting electrolytes have on electrochemically-triggered reactions, and provide a strategy for inducing or preventing alkoxyamine cleavage, depending on the desired outcome. This is important as when cleavage is suppressed, high voltage alkoxyamine oxidation is potentially useful for energy storage applications, while when promoted it can offer an in situ "on-demand" $\mathrm{S}_{\mathrm{N}} 2$-method for alkylation or fluorination.

\section{ASSOCIATED CONTENT}

Supporting Information Complete experimental and computational data. The Supporting Information is available free of charge on the ACS Publications website.

\section{AUTHOR INFORMATION}

\section{Corresponding Author}

* Email: michelle.coote@anu.edu.au

*Email: simone.ciampi@curtin.edu.au

\section{Author Contributions}

The manuscript was written through contributions of all authors. All authors have given approval to the final version of the manuscript.

\section{Funding Sources}

Australian Research Council (CE140100012, FL170100041, DE160100732)

\section{ACKNOWLEDGMENT}

The authors acknowledge financial support from the Australian Research Council (ARC) Centre of Excellence for Electromaterials Science, an ARC Laureate Fellowship (to M.L.C.), an ARC DECRA Fellowship (to S.C) and generous supercomputing time from the National Computational Infrastructure. 


\section{REFERENCES}

1. Solomon, D. H.; Rizzardo, E.; Cacioli, P. Polymerization Process and Polymers Produced Thereby. 1986 US patent 4,581,429.

2. Georges, M. K.; Veregin, R. P. N.; Kazmaier, P. M.; Hamer, G. K., Narrow Molecular-Weight Resins by a Free-Radical Polymerization Process. Macromolecules 1993, 26, 2987-2988.

3. Hawker, C. J.; Bosman, A. W.; Harth, E., New Polymer Synthesis by Nitroxide Mediated Living Radical Polymerizations. Chem. Rev 2001, 101, 3661-3688.

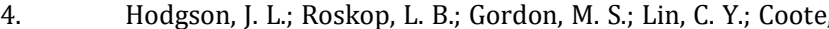
M. L., Side Reactions of Nitroxide-Mediated Polymerization: N-O Versus 0-C Cleavage of Alkoxyamines. J. Phys. Chem. A 2010, 114, 10458-10466.

5. Gryn'ova, G.; Lin, C. Y.; Coote, M. L., Which Side-Reactions Compromise Nitroxide Mediated Polymerization? Polym. Chem. 2013 4, 3744-3754

6. Albergaria Pereira, B. d. F.; Tardy, A.; Monnier, V.; Guillaneuf, Y.; Gigmes, D.; Charles, L., Elucidation of a Side Reaction Occurring During Nitroxide-Mediated Polymerization of Cyclic Ketene Acetals by Tandem Mass Spectrometric End-Group Analysis of Aliphatic Polyesters. Rapid Commun. Mass Spec. 2015, 29, 2302-2308.

7. Morris, J.; Telitel, S.; Fairfull-Smith, K. E.; Bottle, S. E.; Lalevé e, J.; Clément, J.-L.; Guillaneuf, Y.; Gigmes, D., Novel Polymer Synthesis Methodologies Using Combinations of Thermally- and Photochemically-Induced Nitroxide Mediated Polymerization. Polym. Chem. 2015, 6, 754-763.

8. Huix-Rotllant, M.; Ferré, N., Theoretical Study of the Photochemical Initiation in Nitroxide-Mediated Photopolymerization. J. Phys. Chem. A 2014, 118, 4464-4470.

9. $\quad \mathrm{Su}$ J.; Liu, X.; Hu, J.; You, Q.; Cui, Y.; Chen, Y., Photo-Induced Controlled Radical Polymerization of Methyl Methacrylate Mediated by Photosensitive Nitroxides. Polym. Int. 2015, 64, 867-874.

10. Atsushi, G.; Yoshinobu, T.; Takeshi, F., Effects of Acetic Anhydride on the Activation and Polymerization Rates in NitroxideMediated Polymerization of Styrene. Chem. Lett. 2000, 29, 788-789.

11. Baumann, M.; Schmidt-Naake, G., Acetic Anhydride Accelerating Agent for Nitroxide-Controlled Free-Radical Copolymerization of Styrene and Acrylonitrile. Macromol. Chem. Phys. 2001, 202, 2727-2731.

12. Gryn'ova, G.; Coote, L. M., Origin and Scope of Long-Range Stabilizing Interactions and Associated SOMO-HOMO Conversion in Distonic Radical Anions. J. Am. Chem. Soc. 2013, 135, 15392-15403.

13. Gryn'ova, G.; Smith, L. M.; Coote, L. M., Computational Design of pH-Switchable Control Agents for Nitroxide Mediated Polymerisation. Phys. Chem. Chem. Phys 2017, 19, 22678-22683.

14. Klinska, M.; Smith, L. M.; Gryn'ova, G.; Banwell, M. G.; Coote, M. L., Experimental Demonstration of pH-Dependent Electrostatic Catalysis of Radical Reactions. Chem. Sci 2015, 6, 5623-5627.

15. Zhang, L.; Laborda, E.; Darwish, N.; Noble, B.B.; Tyrell, J.H.; Pluczyk, S.; Le Brun, A.P.; Wallace, G.G.; Gonzalez, J.; Coote, M.L. et al., Electrochemical and Electrostatic Cleavage of Alkoxyamines. J. Am. Chem. Soc. 2018, 140, 766-774.

16. Ammer, J.; Mayr, H., Photogeneration of Carbocations: Applications in Physical Organic Chemistry and the Design of Suitable Precursors. J. Phys. Org. Chem. 2013, 26, 956-969.

17. Yoshida, J.-i.; Shimizu, A.; Hayashi, R., Electrogenerated Cationic Reactive Intermediates: The Pool Method and Further Advances. Chem. Rev. 2018, 118, 4702-4730.

18. Zhang, L.; Espíndola, R.; Noble, B.; Gonçales, V.; Wallace, G.; Darwish, N.; Coote, M.; Ciampi, S., Switchable Interfaces: Redox Monolayers on $\mathrm{Si}(100)$ by Electrochemical Trapping of Alcohol Nucleophiles. Surfaces 2018, 1, 3-11.

19. Sugihara, S.; Konegawa, N.; Maeda, Y., Hcl-Et2o-Catalyzed Metal-Free Raft Cationic Polymerization: One-Pot Transformation from Metal-Free Living Cationic Polymerization to Raft Radical Polymerization1. Macromolecules 2015, 48, 5120-5131.

20. Aoshima, H.; Uchiyama, M.; Satoh, K.; Kamigaito, M., Interconvertible Living Radical and Cationic Polymerization through Reversible Activation of Dormant Species with Dual Activity. Angew. Chem. 2014, 53, 10932-10936.
21. Zhang, L.; Vogel, Y. B.; Noble, B. B.; Gonçales, V. R.; Darwish, N.; Brun, A. L.; Gooding, J. J.; Wallace, G. G.; Coote, M. L.; Ciampi, S., Tempo Monolayers on Si(100) Electrodes: Electrostatic Effects by the Electrolyte and Semiconductor Space-Charge on the Electroactivity of a Persistent Radical. J. Am. Chem. Soc. 2016, 138, 9611-9619.

22. Hammill, C.L.; Noble, B. B.; Norcott, P. L.; Ciampi, S.; Coote, M. L., Effect of Chemical Structure on the Electrochemical Cleavage of Alkoxyamines. J. Phys. Chem. C 2019 123, 5273-5281.

23. Janoschka, T.; Martin, N.; Martin, U.; Friebe, C.; Morgenstern, S.; Hiller, H.; Hager, M. D.; Schubert, U. S., An Aqueous, Polymer-Based Redox-Flow Battery Using Non-Corrosive, Safe, and Low-Cost Materials. Nature 2015, 527, 78-81.

24. Nishide, H.; Oyaizu, K., Toward Flexible Batteries. Science 2008, 319, 737-738.

25. Suga, T.; Ohshiro, H.; Sugita, S.; Oyaizu, K.; Nishide, H., Emerging N-Type Redox-Active Radical Polymer for a Totally Organic Polymer-Based Rechargeable Battery. Adv. Mat. 2009, 21, 1627-1630.

26. Janoschka, T.; Hager, M. D.; Schubert, U. S., Powering up the Future: Radical Polymers for Battery Applications. Adv. Mat. 2012, 24, 6397-6409.

27. Zhang, K.; Hu, Y.; Wang, L.; Fan, J.; Monteiro, M. J.; Jia, Z., The Impact of the Molecular Weight on the Electrochemical Properties of Poly(Tempo Methacrylate). Polym. Chem. 2017, 8, 1815-1823.

28. $\quad$ Frisch, M. J.; Trucks, G. W.; Schlegel, H. B.; Scuseria, G. E. Robb, M. A.; Cheeseman, J. R.; Scalmani, G.; Barone, V.; Petersson, G. A.; Nakatsuji, H., et al., Gaussian 09 Rev. D.01, Wallingford, CT, 2016.

29. Werner, H. J.; Knowles, P. J.; Knizia, G.; Manby, F. R.; Schütz M.; Celani, P.; Györffy, W.; Kats, D.; Korona, T.; Lindh, R., et al. Molpro, Version 2015.1, Stuttgart 2015.

30. Zhao, Y.; Truhlar, D. G., The M06 Suite of Density Functionals for Main Group Thermochemistry, Thermochemical Kinetics, NonCovalent Interactions, Excited States, and Transition Elements: Two New Functionals and Systematic Testing of Four M06-Class Functionals and 12 Other Functionals. Theor. Chem. Acc 2007, 120, 215-241.

31. $\quad$ Curtiss, L. A.; Raghavachari, K.; Redfern, P. C.; Baboul, A. G.; Pople, J. A., Gaussian-3 Theory Using Coupled Cluster Energies. Chem. Phys. Lett. 1999, 314, 101-107.

32. Izgorodina, E. I.; Brittain, D. R. B.; Hodgson, J. L.; Krenske, E. H.; Lin, C. Y.; Namazian, M.; Coote, M. L., Should Contemporary Density Functional Theory Methods Be Used to Study the Thermodynamics of Radical Reactions? J. Phys. Chem. A 2007, 111, 10754-10768.

33. Coote, M. L.; Krenske, E. H.; Izgorodina, E. I., Computational Studies of RAFT Polymerization-Mechanistic Insights and Practical Applications. Macromol. Rapid Commun. 2006, 27, 473-497.

34. Ho, J.; Klamt, A.; Coote, L. M., Comment on the Correct Use of Continuum Solvent Models. J. Phys. Chem. A 2010, 114, 13442-13444.

35. Marenich, A. V.; Cramer, C. J.; Truhlar, D. G., Universal Solvation Model Based on Solute Electron Density and on a Continuum Model of the Solvent Defined by the Bulk Dielectric Constant and Atomic Surface Tensions. J. Phys. Chem. B 2009, 113, 6378-6396.

36. Kolling, O. W., Comparison of Donor-Acceptor Parameters in Nonaqueous Solvents. Anal. Chem. 1982, 54, 260-264.

37. $\quad$ Cresswell, J. A.; Davies, G. S.; Roberts, M. P.; Thomson, E. J., Beyond the Balz-Schiemann Reaction: The Utility of Tetrafluoroborates and Boron Trifluoride as Nucleophilic Fluoride Sources. Chem. Rev. 2015, 115, 566-611. 
TOC graphic

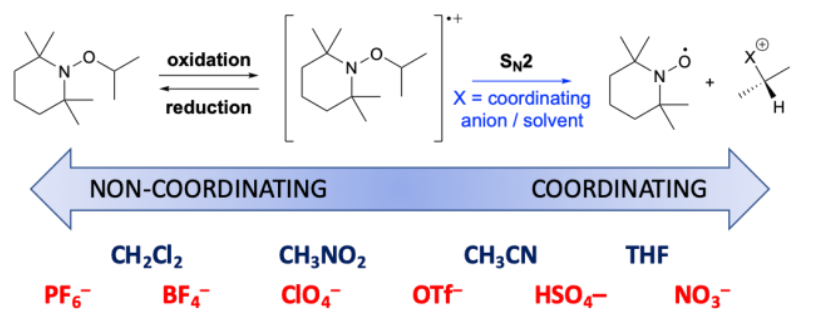

